\title{
Remembering and forecasting: The relation between autobiographical memory and episodic future thinking
}

\author{
DORTHE BERnTSEn AND ANNETTE BoHN \\ Aarhus University, Aarhus, Denmark
}

\begin{abstract}
Episodic future thinking is a projection of the self into the future to mentally preexperience an event. Previous work has shown striking similarities between autobiographical memory and episodic future thinking in response to various experimental manipulations. This has nurtured the idea of a shared neurocognitive system underlying both processes. Here, undergraduates generated autobiographical memories and future event representations in response to cue words and requests for important events and rated their characteristics. Important and wordcued events differed markedly on almost all measures. Past, as compared with future, events were rated as more sensorially vivid and less relevant to life story and identity. However, in contrast to previous work, these main effects were qualified by a number of interactions, suggesting important functional differences between the two temporal directions. For both temporal directions, sensory imagery dropped, whereas self-narrative importance and reference to normative cultural life script events increased with increasing temporal distance.
\end{abstract}

I was wondering what I would have for lunch and had an image of opening my refrigerator and taking out a liverpate. In my imagination, I looked if I had other things in the refrigerator. (Female, 26 years)

I was looking out the window and there was a gray-blue sky and then I happened to imagine my wedding - the moment when I walk from my parents' house to the church and there are flowers and sunshine and wind catches the veil. (Female, 24 years)

Episodic future thinking is "a projection of the self into the future to pre-experience an event" (Atance \& O'Neill, 2001, p. 533). As is illustrated by the two examples above (Berntsen \& Jacobsen, 2008), imagined future events share many similarities with autobiographical memories of past events. As with memories, imagined future events can be about mundane experiences (e.g., imagining having lunch), as well as about highly significant personal events (e.g., envisioning one's wedding). As with memories, they can be temporally close as well as distant. Importantly, both memories and imagined future events involve mental time travel - that is, the process of projecting oneself forward or backward in time and mentally envisioning oneself actually being situated in the past or future event (Suddendorf \& Corballis, 2007; Tulving, 1985). Both processes thus involve sensory and spatial imagery, as well as emotion and knowledge of the self.

More than 20 years ago, Tulving (1985) reformulated his notion of episodic memory to include the ability to mentally project oneself into possible future events. Recently, however, cognitive psychology and cognitive neuroscience have witnessed an upsurge in experimental studies directly examining the relation between episodic remembering and episodic future thinking (for reviews, see Schacter, Addis, \& Buckner, 2007; Suddendorf \& Corballis, 2007; Szpunar, in press). Converging evidence from such studies suggests that episodic remembering and episodic future thinking are supported by the same neurocognitive processes. Brainimaging studies have shown high degrees of overlapping neural activity in prefrontal and medial temporal lobe regions, as well as posterior regions, when subjects are asked to remember past versus imagine future events (e.g., Addis, Wong, \& Schacter, 2007; Botzung, Denkova, \& Manning, 2008; Okuda et al., 2003; Szpunar, Watson, \& McDermott, 2007), supporting the idea of a core brain network engaged in both processes (Schacter et al., 2007). Patients with traumatic brain injury who have an inability to recollect past events are also unable to imagine personal events (Hassabis, Kumaran, Vann, \& Maguire, 2007; Klein, Loftus, \& Kihlstrom, 2002; Tulving, 1985). Past and future mental time travel are affected in similar ways by instructions to generate external versus internal events (Larsen, 1998) and positive versus negative events (D'Argembeau \& Van der Linden, 2004; Larsen, 1998), as well as events at different temporal distances from the present (Addis, Wong, \& Schacter, 2008; D’Argembeau \& Van der Linden, 2004). Both types of representations have been found to occur involuntarily (spontaneously, with no intent) as well as voluntarily (Berntsen \& Jacobsen, 2008). Past and future mental time travel seem to develop around the same time in the 
preschool years (Atance, 2008; Suddendorf \& Corballis, 2007), to be affected similarly by aging (Addis et al., 2008), and to show similar deficits in mental disorders, such as depression and schizophrenia (D'Argembeau, Raffard, \& Van der Linden, 2008; Williams et al., 1996).

This parallelism between episodic remembering and episodic future thinking has led to a new functional perspective on memory, according to which the most important function of episodic memory may be to enable individuals to imagine possible future (or otherwise nonexisting) events (e.g., Schacter \& Addis, 2007; Schacter et al., 2007). In order to serve the construction of future events, episodic memory needs to be a flexible system that allows stored details to be extracted and recombined into representations of events that have not yet occurred (Schacter et al., 2007). This helps to explain why episodic memory is sometimes inaccurate and why episodic remembering and episodic future thinking show similar neural activation and similar effects of various experimental manipulations. However, in spite of these parallels, studies have consistently shown a number of differences between episodic remembering and episodic future thinking, which have been little discussed. They do not necessarily contradict the idea that episodic remembering and future thinking are served by the same underlying neurocognitive system. However, they do suggest that the two processes interact differently with components of such a possibly underlying system. The purpose of the present work was to examine the nature of such interactions.

\section{Effects of Past Versus Future Temporal Direction}

Differences between episodic remembering and future thinking can be summarized in terms of two overarching findings: Episodic future thinking appears to require more constructive effort and is more emotionally positive and idyllic than episodic remembering.

First, several findings suggest that it is cognitively more demanding to imagine personal events in the future than it is to remember events from the past. Brain-imaging studies have shown more activity when subjects are imagining future events, as compared with remembering past events (Addis et al., 2007; Szpunar et al., 2007). This may suggest that episodic future thinking requires more schema-driven construction than does episodic remembering, which is consistent with findings at the behavioral level. For example, imagined future events contain fewer sensory details (Addis et al., 2008; Berntsen \& Jacobsen, 2008; D'Argembeau \& Van der Linden, 2004; Larsen, 1998) and more observer perspective (D'Argembeau \& Van der Linden, 2004) and refer less frequently to specific episodes (Addis et al., 2008; Berntsen \& Jacobsen, 2008) than do memories of past events. Patients with schizophrenia record substantially fewer specific events in the future than in the past condition, as compared with controls (D'Argembeau et al., 2008). Subjects rate imagined future events as more personally significant than remembered past events (Addis et al., 2008; D'Argembeau \& Van der Linden, 2004; Newby-Clark \& Ross, 2003), which suggests that future events are more closely associated with the self-schema and other types of generic autobiographi- cal knowledge (Conway, 2005). Although the time distribution of remembered past events and imagined future events can be accounted for by the same mathematical function, the slope for the future condition is steeper than the slope for the past condition, reflecting the fact that representations of future events are sampled temporally closer to the present than are past events (Berntsen \& Jacobsen, 2008; Spreng \& Levine, 2006). This is consistent with the idea that episodic future thinking requires more constructive effort as one moves further from the present.

Second, autobiographical memory studies show that healthy subjects recall roughly twice as many positive as negative events from their past (Walker, Skowronski, \& Thompson, 2003). However, this positivity bias is even more pronounced for episodic future thinking. In a diary study of involuntary and voluntary mental time travel into the past and future, Berntsen and Jacobsen (2008) found a dominance of positive events, relative to negative ones, in all four conditions, but more so for the two future than for the two past event conditions. Newby-Clark and Ross (2003) asked college students to list a maximum of 10 important events from their past, as well as 10 important events from their futures. The future events were rated as significantly more positive than the past events. In a number of additional studies, Newby-Clark and Ross found that their subjects were slower at generating negative than positive future events, whereas no such difference was observed for past events (but see Lishman, 1974). Lachman, Röcke, Rosnick, and Ryff (2008) studied trajectories of life satisfaction in a large national sample of Americans. Up to an age of 65, life satisfaction was rated higher for the future than for the present and higher for the present than for the past. Subjects between the ages of 65 and 75 still rated the expected future more satisfactory than the past, whereas no difference was observed between ratings of the future and the present. Only for the oldest group (age, 75-84 years) did ratings of present and past life satisfaction exceed ratings of expected life satisfaction in the future. Thus, the future keeps looking brighter than the past up to an age of 75 .

We shall argue that these differences between episodic memories and episodic future thinking reflect the fact that the former, in contrast to the latter, refer to events that have been experienced and encoded, for which reason representations of past events, to a greater extent than representations of future events, are influenced by factors that are known to affect encoding and maintenance, such as emotional arousal (e.g., McGaugh, 2003, 2004) and perceived importance (e.g., Pillemer, 1998). The construction of future events, on the other hand, is guided by schematized regularities and uncorrected positive illusions (Taylor \& Brown, 1988) to a greater extent than is the construction of memories. We probed this effect here by asking subjects to generate important versus word-cued events in both temporal conditions.

\section{Effects of Temporal Distance: The Role of Cultural Life Scripts}

Irrespective of past versus future temporal direction, representations of temporally distant events differ from those of temporally close events. Ratings of personal sig- 
nificance are higher for temporally remote than for close future/past events (Addis et al., 2008; D'Argembeau \& Van der Linden, 2004), whereas levels of sensory detail and clarity show the opposite pattern (Addis et al., 2008; D'Argembeau \& Van der Linden, 2004; Szpunar $\&$ McDermott, 2008). These findings agree with temporal construal theory (Trope \& Liberman, 2003), according to which representations of temporally remote events are more abstract and, thus, more schema based than are representations of temporally close events. One possible mediator for these effects may be the cultural life script (Berntsen \& Rubin, 2004) - that is, a culturally shared representation of normative life events and their expected timing (such as getting married around the age of 26). The concept of life script combines the idea of culturally sanctioned age norms, as studied in anthropology and sociology (e.g., Neugarten, Moore, \& Lowe, 1965), with the concept of script, as this notion was developed by Schank and Abelson (1977) in cognitive psychology (see Berntsen $\&$ Rubin, 2004, for a review). Previous work has shown that life scripts are strongly biased in favor of positive events and events that are expected to take place in young adulthood (see Rubin, Berntsen, \& Hutson, 2009, for a review). Although life scripts help to structure individual life narratives, the two concepts are theoretically and empirically distinct. A life script is a culturally shared part of our semantic knowledge, whereas a life story is personal, in that it belongs to a specific individual and is part of our autobiographical knowledge (Berntsen \& Rubin, 2004; Bohn, in press; Bohn \& Berntsen, 2008; Rubin et al., 2009).

Cultural life scripts are likely to influence the search descriptions that people use when asked to recall memories in response to various cues. As was pointed out by Berntsen and Rubin (2004), a request for important memories is more likely to activate the life script than is a request to retrieve autobiographical memories through more associative means, such as in response to random word cues. To date, only one study has examined the role of life scripts for episodic future thinking. Berntsen and Jacobsen (2008) found no overall difference between episodic future thinking and episodic remembering concerning the overlap with cultural life script events. However, for both temporal directions, the overlap with life script events increased with increasing temporal distance from the present, suggesting that life scripts may be especially central for our ability to mentally travel into the more distant past and future.

\section{The Study}

We sampled future and past event representations in two different ways: one that was expected to accentuate an effect of encoding and maintenance and one that was not. We did so by asking our subjects for important versus word-cued representations of future and past events. We know from studies on autobiographical memory that a request to retrieve important events gives access to perceptually rich representations of events that were often experienced as emotional and consequential when they took place (e.g., Pillemer, 1998, 2003; Singer \& Salovey,
1993), which are factors known to affect encoding and maintenance. The cue word technique, on the other hand, was introduced by Galton (1907) and adapted by Crovitz and Schiffman (1974) as a way to achieve a representative sample of the multitude of diverse autobiographical events that any individual is expected to hold in his or her longterm memory. It is thus conceived as a random-sampling technique. The cue word technique has been used in a number of studies comparing episodic remembering and episodic future thinking (e.g., Addis et al., 2007), but it has never been contrasted with sampling through a request for important events.

Only one study has compared the two sampling techniques, and only for past events. Rubin and Schulkind (1997a) asked old and young subjects to retrieve $5 \mathrm{im}$ portant autobiographical memories and 124 word-cued autobiographical memories and to rate these memories on a number of scales. The important memories were rated as more sensorially vivid, more significant, more novel, more emotional, and more frequently rehearsed than the wordcued memories. These findings agree well with Singer and Salovey's (1993) notion of self-defining memoriesin that such memories are expected to be more vivid, more emotional, and more relived and rehearsed than are mundane memories.

Following these studies, we expected the request for important events to yield higher scores on most phenomenological measures in both the future and past conditions, as compared with the word-cued counterparts. However, at the same time, we expected such a main effect to be qualified by a number of interactions due to the important past condition's accentuating an encoding and maintenance effect that would be absent from (or considerably reduced for) the future condition. In other words, we expected important and word-cued events to differ more from one another in the past condition than in the future condition on measures related to subjective clarity, emotion, and rehearsal frequency.

With regard to the effect of future versus past temporal direction, we expected future events to be rated as less sensorially vivid than past events, consistent with previous work (Addis et al., 2008; Berntsen \& Jacobsen, 2008; D'Argembeau \& Van der Linden, 2004; Larsen, 1998). Also, consistent with previous work, we expected future events to be rated as more positive and idyllic (Berntsen \& Jacobsen, 2008; Newby-Clark \& Ross, 2003), more personally significant (Addis et al., 2008; D’Argembeau \& Van der Linden, 2004; Newby-Clark \& Ross, 2003) and, thus, as more central to life story and identity, as compared with memories of past events. Because we expected the construction of future events to draw more on schematized knowledge than would past events, we expected the former to show a higher overlap with cultural life script events, although Berntsen and Jacobsen failed to find such an effect, except for temporally distant events.

Irrespective of temporal direction, we expected temporally distant events to show greater overlap with cultural life script events (Berntsen \& Jacobsen, 2008) and to have more relevance to life story and identity than would temporally close events (Addis et al., 2008; D’Argembeau 
$\&$ Van der Linden, 2004). We expected the reverse pattern for vividness and sensory details (Addis et al., 2008; D'Argembeau \& Van der Linden, 2004; Szpunar \& McDermott, 2008).

\section{METHOD}

\section{Subjects}

The subjects were 122 psychology students (103 females; mean age, 26.53 years; range, 21-47), who took part in the study as part of a teaching course.

\section{Design}

We used a 2 (important vs. word-cued) $\times 2$ (future vs. past) withinsubjects design with the order of the four event conditions randomized between the subjects. There were five events in each condition; thus, each subject recorded a total of 20 event representations.

\section{Materials}

The subjects were equipped with a booklet with the four event conditions (important past, important future, word-cued past, wordcued future) presented in blocks of five events. Each event request was printed on a separate page in the booklet. Each block was preceded by a brief written instruction. The instructions for the wordcued past condition were the following:

On the following pages you will be asked to recall five memories from your personal life in response to five different cue words. You should describe the first memory that comes to your mind in response to each word. The memory can come from any point in your life. It can be from yesterday or deal with something that happened many years ago. The memory has to be about a specific event. This means that it should deal with something that happened to you on a specific day in your past. After you have recalled an event you will be asked to answer a number of questions about it.

The instructions for the word-cued future events were exactly the same, except for the reference to imagined future events instead of remembered past events. The cue words were bed, bread, book, car, chair, dog, glass, house, kitchen, and telephone. They were chosen because they are highly concrete and associative (Brown \& Ure, 1969). Furthermore, they were matched for prevalence in Danish (Bergenholtz, 1992). The instructions for the important past condition were the following:

On the following pages you will be asked to recall five memories of important events in your life and provide a short descrip- tion of each of them. The memory can come from any point in your life. It can be from yesterday or deal with something that happened many years ago. The memory has to be about a specific event. This means that it should deal with something that happened to you on a specific day in your past. After you have recalled an important event you will be asked to answer a number of questions about it.

The instructions for the important future events were exactly the same, except for the reference to imagined future events instead of remembered past events.

In all four parts of the experiment, the subjects answered a series of 14 questions to each remembered/imagined event. The questions were modified from Rubin, Schrauf, and Greenberg (2003) and Berntsen and Jacobsen (2008). Two questions derived from the Centrality of Event Scale (CES; Berntsen \& Rubin, 2006) and were rated on 5-point scales. Most other questions were rated on 7-point scales. Table 1 presents the questions as they were asked for the two past conditions (the labels in the parentheses indicate the labels used in the tables for the results and in the analyses; response options are indicated in the parentheses that follow each question). For the two future conditions, the questions were exactly the same, except that the wordings were changed to refer to future events (Question 12 forms an exception, because it had to be formulated differently to make sense in relation to the future; see Table 1).

\section{Procedure}

The subjects were tested in a group setting. The experimenter initially informed them about the four event tasks and the questions. Then the subjects were handed the booklets and were asked to go through the tasks in the booklet at their own pace. All the subjects finished this task within $90 \mathrm{~min}$. After the booklets were completed, the subjects were instructed to classify their recorded events according to the 36 event categories for the cultural life script (including "other") identified by Berntsen and Rubin (2004, Table 3). For an overview of these categories, see Table 4 . The content of each of these life script event categories was carefully explained by the experimenter. After each description, the subjects were asked to look through the events that they had generated and indicate whether any of these events corresponded to the described category. This selfcoding procedure was used in previous studies and yielded results that were highly similar to experimenter-coded event categories (Rubin et al., 2009).

\section{Scoring}

Categories of non-life-script events. All memories and future event representations that were scored as noncultural life script events by the subjects (i.e., events that were scored as "other") were catego-

Table 1

Questions Answered for Each Remembered Event

1. (Age at event) How old were you when the remembered event took place? (age estimated in years).

2. (Days ago) If you indicated your current age in question number 1, how many days from today is the event in the past? (time estimated in days).

3. (Vividness) This memory is vivid ( $1=$ not at all; $7=$ to a very high degree $)$.

4. (P/reexperience) When I recollect the event, it is as if I am reexperiencing it $(1=$ not at all; $7=$ to a very high degree).

5. (Visual/auditory) When I think of the episode, I can see and hear in my mind what took place $(1=$ not at all; $7=$ to $a$ very high degree).

6. (Perspective) When I recall the event, I primarily see what happened from a perspective as seen through $(1=m y$ own eyes; $7=$ an observer's eyes).

7. (Valence) The emotions I have when I recall the episode are $(-3=$ extremely negative; $3=$ extremely positive $)$.

8. (Intensity) The emotions I have when I recall the episode are intense $(1=$ not at all; $7=$ to a very high degree $)$.

9. (Thought/talked) Since it happened, I have thought and talked a lot about this episode ( $1=$ not at all; $7=$ very often).

10. (Importance) The remembered event is important to my life $(1=$ not at all; $7=$ to a very high degree).

11. (Reaction) I had a physical/bodily reaction to the memory-for example, by talking to myself, smiling, crying, shivering, palpitation, laughing, hitting things, etc. $(1=$ not at all; 7 = to a very high degree $)$.

12. (Belief) I believe that the event really took place the way I remember it, and that I did not imagine anything or invent anything that did not take place $(1=100 \%$ fantasy; $7=100 \%$ real $)$. For the future conditions this question was formulated as "How likely is it that the imagined event will take place in your future?" ( 1 = not at all likely; 7 = completely likely).

13. (Identity) I feel this event has become part of my identity $(1=$ totally disagree; $5=$ totally agree $)$.

14. (Life story) I feel that this event has become a central part of my life story $(1=$ totally disagree; $5=$ totally agree $)$ 
rized by two independent raters, using the 17 memory content categories developed by Schlagman, Schulz, and Kvavilashvili (2006). The 17 categories were person (i.e., primarily about other people); accidents including injuries and illnesses; stressful events (i.e., psychological stress); holidays; conversations; leisure/sports activities; objects/places; going out; work/university; romantic involvement; school (elementary and high school); deaths/funerals; special occasions (e.g., birthdays, weddings); births; traveling/journeys; war/ army; and miscellaneous. Interrater reliability was good (Cohen's $\kappa=$ .799). Disagreements were solved by a third judge.

Idyll. Two raters scored all memories and future event representations on a 3-point rating scale on how idyllic they were (Berntsen \& Jacobsen, 2008). A maximum idyll score of 3 was given if the record described a situation that most people would find attractive and if the description did not contain any indications of negative emotion. A score of 2 was given if one, but not both, of the two idyll indicators (attractive situation, absence of negative emotions) could be confirmed. If none of the two indicators could be confirmed, the record received an idyll score of 1 . Interrater agreement was high (Cronbach's $\alpha=.94$ ). Disagreements were resolved by a third judge.

\section{RESULTS}

First, we describe characteristics of the remembered/ imagined past versus future events as a function of activation through word cues versus requests for important events. Second, we examine the content of the remembered and imagined events. Third, we examine the characteristics of the remembered and imagined events as a function of their distance from the present. Finally, through a series of regression analyses, we examine whether the subjective characteristics of the four event categories show similar correlational patterns. Such analyses have been conducted for autobiographical memories of past events (e.g., Rubin, 2006; Rubin et al., 2003), but they have never been extended to representations of future events.

Because each subject provided five event records in each of the four event conditions, the individual event records could not be treated as independent observations. For that reason, the statistical analyses are largely based on means calculated for each subject in each event condition or on multiple regression analyses with dummycoded subject variables to control for subject variability. The dummy-coded subject variables are included in the regression analyses as independent variables that distinguish that part of the total variance that comes from each subject. With this method, each observation can be legitimately treated as independent (Cohen \& Cohen, 1983; Thompson, Skowronski, Larsen, \& Betz, 1996).

\section{Future Versus Past Events in the Word-Cued Versus Important Conditions}

Table 2 shows the means and standard deviations for the four categories of events, as well as main effects and interactions. As was expected, word-cued versus important events differed significantly on almost all included measures. Exceptions were perspective, valence, and distance in years, for which prior work yielded no specific predictions. As is also shown in Table 2, the great majority (71\%) of the important events in both the future and past conditions referred to life script events, whereas this was the case for only a minority of the word-cued future and past events. This clearly shows that the cuing technique affects the extent to which life scripts are activated (Berntsen \& Rubin, 2004).

Memories of past events were rated higher on vividness, p/reexperience, and visual-auditory imagery, whereas representations of future events were rated higher on observer perspective, personal importance, and relevance to life story and identity and were less distant in time. These findings are consistent with earlier work showing that future episodic thinking involves less sensory imagery and more schemabased construction than does episodic remembering. In contrast to our prediction, future events did not refer more

Table 2

Characteristics of Word-Cued Versus Important Future Versus Past Event Representations

\begin{tabular}{|c|c|c|c|c|c|c|c|c|c|c|c|c|c|c|}
\hline \multirow[b]{4}{*}{ Dependent Variable } & \multirow{2}{*}{\multicolumn{4}{|c|}{ Past Events }} & \multirow{2}{*}{\multicolumn{4}{|c|}{ Future Events }} & \multicolumn{4}{|c|}{ Main Effects } & & \\
\hline & & & & & & & & & \multirow{2}{*}{\multicolumn{2}{|c|}{$\begin{array}{l}\text { Cue Word vs. } \\
\text { Important }\end{array}$}} & \multirow{2}{*}{\multicolumn{2}{|c|}{ Future vs. Past }} & \multirow{2}{*}{\multicolumn{2}{|c|}{ Interaction }} \\
\hline & \multicolumn{2}{|c|}{ Cue Word } & \multicolumn{2}{|c|}{ Important } & \multicolumn{2}{|c|}{ Cue Word } & \multicolumn{2}{|c|}{ Important } & & & & & & \\
\hline & $M$ & $S D$ & $M$ & $S D$ & $M$ & $S D$ & $M$ & $S D$ & $F$ & $\eta_{\mathrm{p}}^{2}$ & $F$ & $\eta_{\mathrm{p}}^{2}$ & $F$ & $\eta_{\mathrm{p}}^{2}$ \\
\hline Vividness & 5.04 & 0.94 & 5.69 & 0.78 & 4.66 & 1.17 & 4.70 & 1.20 & $23.08^{* * *}$ & .16 & $68.58^{* * *}$ & .37 & $29.73^{* * *}$ & .20 \\
\hline $\mathrm{P} /$ reexperience & 4.23 & 1.12 & 4.88 & 1.14 & 4.27 & 1.31 & 4.32 & 1.24 & $25.25^{* * *}$ & .18 & $8.15^{* *}$ & .07 & $22.90^{* * *}$ & .16 \\
\hline Visual-auditory & 4.49 & 0.91 & 5.15 & 0.92 & 4.16 & 1.17 & 3.97 & 1.22 & $12.83^{* *}$ & .10 & $90.51^{* * *}$ & .44 & $44.82^{* * *}$ & .27 \\
\hline Perspective & 2.96 & 1.40 & 2.92 & 1.32 & 3.34 & 1.45 & 3.59 & 1.41 & 1.34 & .01 & $23.34^{* * *}$ & .17 & 2.87 & .02 \\
\hline Intensity & 3.59 & 1.10 & 4.87 & 1.12 & 3.63 & 1.27 & 4.72 & 1.32 & $194.63^{* * *}$ & .62 & 0.37 & .00 & 2.22 & .02 \\
\hline Valence & 0.54 & 0.77 & 0.50 & 0.93 & 1.29 & 0.67 & 1.55 & 0.88 & 2.78 & .02 & $167.29^{* * *}$ & .59 & $4.06^{*}$ & .03 \\
\hline Reaction & 2.79 & 1.33 & 3.64 & 1.52 & 2.66 & 1.23 & 3.64 & 1.57 & $96.15^{* * *}$ & .45 & 0.58 & .01 & 1.05 & .01 \\
\hline Thought/talked & 3.36 & 1.13 & 4.96 & 1.00 & 3.28 & 1.17 & 4.51 & 1.27 & $270.29^{* * *}$ & .70 & $8.58^{* *}$ & .07 & $6.27^{* *}$ & .05 \\
\hline Belief & 5.87 & 0.95 & 6.12 & 0.76 & 5.86 & 0.79 & 6.02 & 0.61 & $15.90^{* *}$ & .12 & 0.35 & .00 & 0.85 & .01 \\
\hline Importance & 2.72 & 1.07 & 5.46 & 0.98 & 3.51 & 1.16 & 5.90 & 0.75 & $792.75^{* * *}$ & .87 & $63.13^{* * *}$ & .35 & $6.14^{*}$ & .05 \\
\hline Identity & 2.00 & 0.77 & 3.75 & 0.82 & 2.46 & 0.82 & 3.93 & 0.69 & $669.06^{* * *}$ & .85 & $29.54^{* * *}$ & .20 & $7.71^{* *}$ & .06 \\
\hline Life story & 1.98 & 0.77 & 3.86 & 0.74 & 2.39 & 0.82 & 4.09 & 0.70 & $746.06^{* * *}$ & .86 & $33.87^{* * *}$ & .22 & 2.92 & .02 \\
\hline Life script & 0.20 & 0.22 & 0.71 & 0.23 & 0.25 & 0.25 & 0.71 & 0.22 & $558.99^{* * *}$ & .82 & 1.64 & .01 & 2.63 & .02 \\
\hline Distance, years & 9.33 & 6.26 & 6.67 & 4.43 & 4.24 & 3.08 & 5.76 & 4.09 & 2.91 & .03 & $36.61^{* * *}$ & .26 & $34.25^{* * *}$ & .26 \\
\hline \multicolumn{15}{|l|}{ Composite scores } \\
\hline Imagery & 4.60 & 0.88 & 5.25 & 0.85 & 4.38 & 1.14 & 4.33 & 1.14 & $22.79^{* * *}$ & .17 & $54.63^{* * *}$ & .33 & $43.22^{* * *}$ & .28 \\
\hline Self-narrative & 2.77 & 1.02 & 5.37 & 0.95 & 3.43 & 1.08 & 5.71 & 0.81 & $848.34^{* * *}$ & .88 & $47.68^{* * *}$ & .28 & $6.07^{*}$ & .05 \\
\hline
\end{tabular}

Note- $d f$ range: $1,102-1,120 .{ }^{*} p<.05 .{ }^{* *} p<.01 .{ }^{* * *} p<.0001$ 
frequently than past events to cultural life script events. We replicated earlier work showing that representations of future events are considered significantly more emotionally positive than are memories of past events.

As was predicted, these main effects were qualified by a number of interactions. An inspection of the means in Table 2 shows that in the majority of cases, these interactions were due to the word-cued versus important manipulation having a larger effect in the past than in the future condition, consistent with the idea that the request for important events accentuates an encoding and maintenance effect that is present for the past and absent from (or considerably reduced for) the future condition. Notably, important past events were rated higher than word-cued past events on vividness, p/reexperience, and visual-auditory imagery (all $p \mathrm{~s}<.0001$ ), whereas no significant differences were observed in the future condition (all $p \mathrm{~s}>.08$ ). A similar pattern was seen for thought/talked, importance, and identity. Although these variables were rated higher for the important events in both temporal conditions, the difference between important versus word-cued events was more pronounced for the past conditions, which explains the interactions (see Table 2).

The interaction for valence reflected the fact that important events were rated more positive than were word-cued events in the future condition $[t(120)=3.06, p<.01]$, but not in the past condition $(t<1)$. Although the means for emotional valence were similar for the word-cued and important past events, their distribution of emotion ratings were, nonetheless, very different (see Table 3 ): The wordcued past events tended to show a normal distribution, with emotion ratings centered around 0 on the -3 to 3 rating scale, whereas the important past events showed a U-shaped distribution, with relatively many cases scored at the extreme ends of the emotion scale and fewer in the middle. A Spearman rank order correlation analysis based on the means in Table 3 confirmed that the distributions of emotion ratings for the two past event categories were different $[R(5)=-.07, p>.8]$. In contrast, the emotion ratings for the important and word-cued future events showed highly correlated distributions of the means $[R(5)=.92$, $p<.01$ ], primarily because both event categories were highly dominated by emotion scores in the positive and highly positive end of the emotion scale (see Table 3 ). The fact that only important past events showed a U-shaped distribution of emotion ratings agrees with our claim that a request for important past events accentuates an encoding and maintenance effect, since emotional arousal—and negative emotional arousal, in particular - tend to lead to fast and enduring learning (see Cacioppo \& Gardner, 1999, for a review). As we will clarify in the next section, a substantial part of the important past events referred to highly stressful or traumatic experiences, whereas this was considerably less the case for the word-cued memories and hardly ever the case for the future events. In general, the important past events seemed to have a special status, in that they were rated higher than any of the other three event categories on vividness, p/reexperience, visualauditory, and thought/talked (all $p \mathrm{~s}<.0001$ ).

For event age, the interaction depicted in Table 2 reflected the fact that the word-cued past events were markedly more distant in time than were the important past events $[t(114)=5.11, p<.0005]$, whereas a difference in the opposite direction was found for the future events $[t(106)=3.72, p<.0005]$. The increased event age for the word-cued memories (relative to the other event types) is likely to reflect the use of highly concrete and imaginable cue words in the present study, since such words are known to activate older memories (Rubin \& Schulkind, 1997b). In sum, the findings correct previous work by showing systematic interactions between the word-cued versus important cuing conditions and the past versus future temporal directions.

\section{Content Analyses}

The scores of the content showed systematic differences between the four categories of events. The two future event categories were scored as markedly more idyllic than the past events, in that $76 \%$ of the word-cued and $80 \%$ of the important future events were scored as extremely idyllic against $55 \%$ of both of the corresponding categories for past events. Only $5 \%$ of the word-cued and $8 \%$ of the important future events were scored as not at all idyllic, against $20 \%$ and $25 \%$ of the corresponding categories for past events. The distribution of the idyll scores over the four event categories differed significantly $\left[\chi^{2}(6)=170.46, p<.0001\right]$. The idyll score correlated consistently with emotional valence across all four event categories $(r \mathrm{~s}=.61-.74, p \mathrm{~s}<.0001)$.

Table 4 shows the distribution of the events according to the 35 life script categories identified by Berntsen and Rubin (2004). This table can be seen largely as an illustration of where our young subjects are in life. For the past, they recorded fall in love, college, and long trip as their most dominant life script events, whereas for the future they predominantly envisioned marriage and having chil-

Table 3

Distribution of Ratings for Emotional Valence for Past (Word-Cued vs. Important) and Future (Word-Cued vs. Important) Event Representations (Percentages)

\begin{tabular}{|c|c|c|c|c|c|c|c|}
\hline \multirow[b]{2}{*}{ Event Categories } & \multicolumn{2}{|c|}{$\begin{array}{c}\text { Highly } \\
\text { Negative }\end{array}$} & \multirow[b]{2}{*}{-1} & \multirow[b]{2}{*}{0} & \multirow[b]{2}{*}{1} & \multicolumn{2}{|c|}{ Highly Positive } \\
\hline & -3 & -2 & & & & 2 & 3 \\
\hline Important past & 13.32 & 10.03 & 9.70 & 8.72 & 16.94 & 22.20 & 19.08 \\
\hline Word-cued past & 3.29 & 9.05 & 12.01 & 24.67 & 18.09 & 22.20 & 10.69 \\
\hline Important future & 4.43 & 3.11 & 3.28 & 7.54 & 17.54 & 32.46 & 31.64 \\
\hline Word-cued future & 2.98 & 2.32 & 3.97 & 16.39 & 19.87 & 36.42 & 18.05 \\
\hline
\end{tabular}


Table 4

Percentages of Cultural Life Script Events in Past and Future (Word-Cued and Important) Event Representations

\begin{tabular}{|c|c|c|c|c|}
\hline \multirow[b]{2}{*}{ Life Script Event } & \multicolumn{2}{|c|}{ Past } & \multicolumn{2}{|c|}{ Future } \\
\hline & $\begin{array}{l}\text { Cue Word } \\
(n=118)\end{array}$ & $\begin{array}{l}\text { Important } \\
(n=431)\end{array}$ & $\begin{array}{l}\text { Cue Word } \\
(n=150)\end{array}$ & $\begin{array}{l}\text { Important } \\
(n=432) \\
\end{array}$ \\
\hline Having children & 2.54 & 6.27 & 27.33 & 24.54 \\
\hline Marriage & 2.54 & 2.09 & 14.00 & 14.12 \\
\hline Begin school & 2.54 & 3.02 & - & - \\
\hline College & 4.24 & 16.47 & 3.33 & 14.82 \\
\hline Fall in love & 6.78 & 12.99 & 4.67 & 2.32 \\
\hline Other's death & 5.93 & 6.50 & 6.00 & 1.16 \\
\hline Retirement & - & - & - & 1.39 \\
\hline Leave home & 5.09 & 7.43 & - & 0.23 \\
\hline Parent's death & 1.70 & 3.48 & 2.67 & 7.18 \\
\hline First job & 4.24 & 0.23 & 0.67 & 1.62 \\
\hline Begin daycare & 0.85 & - & - & - \\
\hline Own death & 0.85 & 0.46 & 0.67 & 0.93 \\
\hline Divorce & - & 3.48 & 1.33 & 1.39 \\
\hline Siblings & 2.54 & 2.32 & - & - \\
\hline First friend & 0.85 & 0.23 & - & - \\
\hline Go to school & 3.39 & 2.32 & - & - \\
\hline Puberty & 4.24 & 0.46 & 0.67 & - \\
\hline Grandchildren & - & - & 0.67 & 2.32 \\
\hline Long trip & 11.02 & 10.91 & 4.00 & 9.03 \\
\hline Begin walking & 0.85 & - & - & - \\
\hline Serious disease & 5.09 & 3.02 & 2.00 & 0.23 \\
\hline Major achievement & 4.24 & 6.50 & 10.00 & 3.47 \\
\hline Settle on career & 1.70 & 1.62 & 5.33 & 1.62 \\
\hline First sexual experience & 4.24 & 1.39 & - & - \\
\hline Partner's death & - & 0.23 & 0.67 & - \\
\hline Begin talking & 0.85 & 0.23 & - & - \\
\hline Confirmation & 2.54 & 1.39 & - & - \\
\hline Enter adulthood & 2.54 & 1.39 & 1.33 & 0.23 \\
\hline Having peers & 7.63 & 0.93 & 2.00 & 0.46 \\
\hline Empty nest & 0.85 & 0.46 & 1.33 & 1.16 \\
\hline First rejection & 0.85 & 1.62 & - & - \\
\hline The "right" job & 0.85 & 1.16 & 7.33 & 10.88 \\
\hline First contact & 6.78 & 1.16 & - & 0.23 \\
\hline Baptism & - & 0.23 & 0.67 & - \\
\hline Earn first money & 1.70 & - & 3.33 & 0.69 \\
\hline Total percent & 100.05 & 100.00 & 100.00 & 100.02 \\
\hline
\end{tabular}

Note-The categories are from Berntsen and Rubin (2004).

dren. Because not all event records could be identified according to one of the life script categories, a variable number of non-life-script events was seen for all four event types. Table 5 shows the distribution of such non-life-script events according to the 17 content categories identified by Schlagman et al. (2006). Table 5 shows that accidents/ illnesses and stressful events accounted for $34 \%$ of the important past (non-life-script) events and $15 \%$ of the wordcued past events, whereas these negative event categories were extremely rare in the two future conditions.

\section{Event Characteristics As a Function of Temporal Distance}

To examine the relation between temporal distance and other characteristics of the imagined and remembered events, we classified the recorded events according to four time bins ( $<1$ year, $\geq 1$ year and $\leq 2$ years, $\geq 3$ years and $\leq 5$ years, and $>5$ years from the present). Because the events were freely sampled with regard to temporal location, and because the important and wordcued events did not show the same distribution across time, the number of observations in each of the four time bins varied across the four event categories, but all included more than 60 observations. The total number of observations in the four bins was $498,427,549$, and 918 . As is illustrated in Figure 1, consistent with our prediction, the prevalence of life script events was considerably higher for temporally distant than for temporally close events. The frequency of life script events tended to increase with increasing temporal distances for all four event categories. As is illustrated in Figure 1, the increase is uniform for the word-cued future events. It is steep for the important past and important future events up to the third time bin. The drop for important events more than 5 years into the past or future may reflect the fact that most of the subjects were in the second decade of their life, in which the frequency of important life script events peaks (Berntsen $\&$ Rubin, 2004). The word-cued past events form a somewhat noisier picture but still show an increase of $100 \%$ across the four time bins depicted in the figure. To examine the relation between temporal distance and reference to life script events more closely, we conducted a multiple 
Table 5

Frequency of Non-Life-Script Events (in Percentages) Across the Four Cuing Conditions

\begin{tabular}{lccccc}
\hline & \multicolumn{2}{c}{ Past } & & \multicolumn{2}{c}{ Future } \\
\cline { 2 - 3 } \cline { 5 - 6 } \multicolumn{1}{c}{ Category } & $\begin{array}{c}\text { Cue Word } \\
(n=469)\end{array}$ & $\begin{array}{c}\text { Important } \\
(n=175)\end{array}$ & & $\begin{array}{c}\text { Cue Word } \\
(n=44)\end{array}$ & $\begin{array}{c}\text { Important } \\
(n=178)\end{array}$ \\
\hline Person & 4.69 & 5.71 & & 4.73 & 7.30 \\
Accidents/illnesses & 9.60 & 13.14 & & 0.45 & 0.56 \\
Stressful events & 5.33 & 21.14 & & 0.45 & 1.12 \\
Holiday & 1.92 & 0.57 & & 1.80 & 7.30 \\
Conversations & 3.63 & 5.71 & & 4.73 & - \\
Leisure/sports & 15.99 & 8.57 & & 21.17 & 7.87 \\
Objects or places & 40.73 & 16.57 & & 48.42 & 32.02 \\
Going out & 1.28 & 2.29 & & 0.90 & 1.12 \\
Work/university & 2.99 & 3.43 & & 6.53 & 7.87 \\
Romantic involvement & 1.71 & 6.86 & & 0.68 & 7.30 \\
School & 1.92 & 3.43 & & - & 2.25 \\
Deaths/funerals & - & 1.14 & & 0.23 & - \\
Special occasions & 4.05 & 4.00 & & 3.83 & 10.67 \\
Births & 0.21 & 2.29 & & - & 4.49 \\
Traveling/journeys & 0.64 & 1.71 & & 0.90 & 3.37 \\
War/army & 0.21 & - & & - & - \\
Miscellaneous & 5.12 & 3.43 & & 5.18 & 6.74 \\
$\quad$ Total percent & 100.02 & 99.99 & & 100.00 & 99.98 \\
\hline
\end{tabular}

Note-The categories are from Schlagman, Schulz, and Kvavilashvili (2006).

regression analysis with life script reference as the dependent variable and temporal distance in years as a predictor variable, together with 121 dummy-coded subject variables included to control for subject variability. We conducted this analysis both with and without events more than 5 years into the past/future filtered out. Temporal distance in years was a significant predictor for life script reference $[t(1350)=15.41, p<.0001, \beta=.40]$ when events more than 5 years into the past/future were filtered out. No significant effect of temporal distance was seen when events more than 5 years in distance were included in the analysis $(p>.07)$. The relation between temporal distance and life script reference across all four event categories supports the idea that cultural life scripts facilitate mental time travel across longer temporal distances than would be possible without such cultural structuring of subjective time (Berntsen, 2009; Berntsen \& Jacobsen, 2008). A similar pattern was seen when temporal distance was measured in days for events that were less than 1 year old, as we will clarify later.

Previous studies on future and past mental time travel have shown that sensory vividness and personal significance appear to follow different patterns regarding both temporal direction and temporal distance. In order to examine these issues here, we calculated two sum scores. We added vividness, p/reexperience, and visual-auditory imagery to form a sum score for imagery and p/reliving (imagery in Table 2). We added importance, identity, and life story ${ }^{1}$ to form a sum score for importance to the self and life narrative (self-narrative in Table 2). Exploratory factor analyses conducted separately for each of the four categories of events showed that the three variables that were included in each of these two sum scores consistently loaded on separate factors (factor loadings ranged from 0.86 to 0.95 for self-narrative variables and from 0.84 to 0.95 for imagery variables, using a Varimax raw rotation).
Cronbach $\alpha$ s ranged from .91 to .89 for self-narrative and from .85 to .93 for imagery. This supports the idea that imagery and self-narrative refer to different dimensions in the characteristics of the past and future event representations. As is shown in Table 2 (and consistent with the individual variables forming the sum scores), imagery was higher for the past, whereas self-narrative was higher for the future, and the interactions largely reflected the special status of the important past condition.

Importantly, imagery and self-narrative were differently related to temporal distance. The top panel of Figure 2 illustrates that imagery drops as a function of distance in time. A multiple regression analysis with imagery as the dependent variable and temporal distance in years as a predictor variable (together with 121 dummy-coded sub-

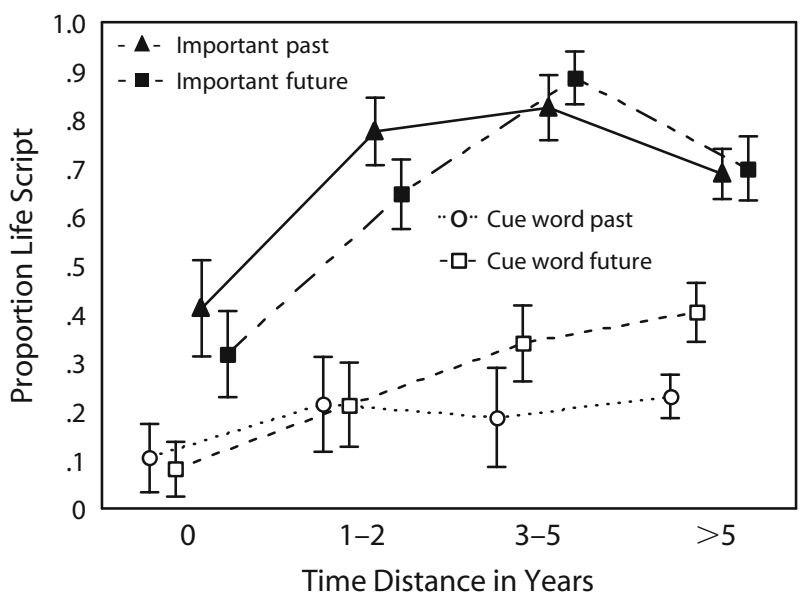

Figure 1. Proportion of life script events as a function of temporal distance to the present as measured in years. Vertical bars denote .95 confidence intervals. 

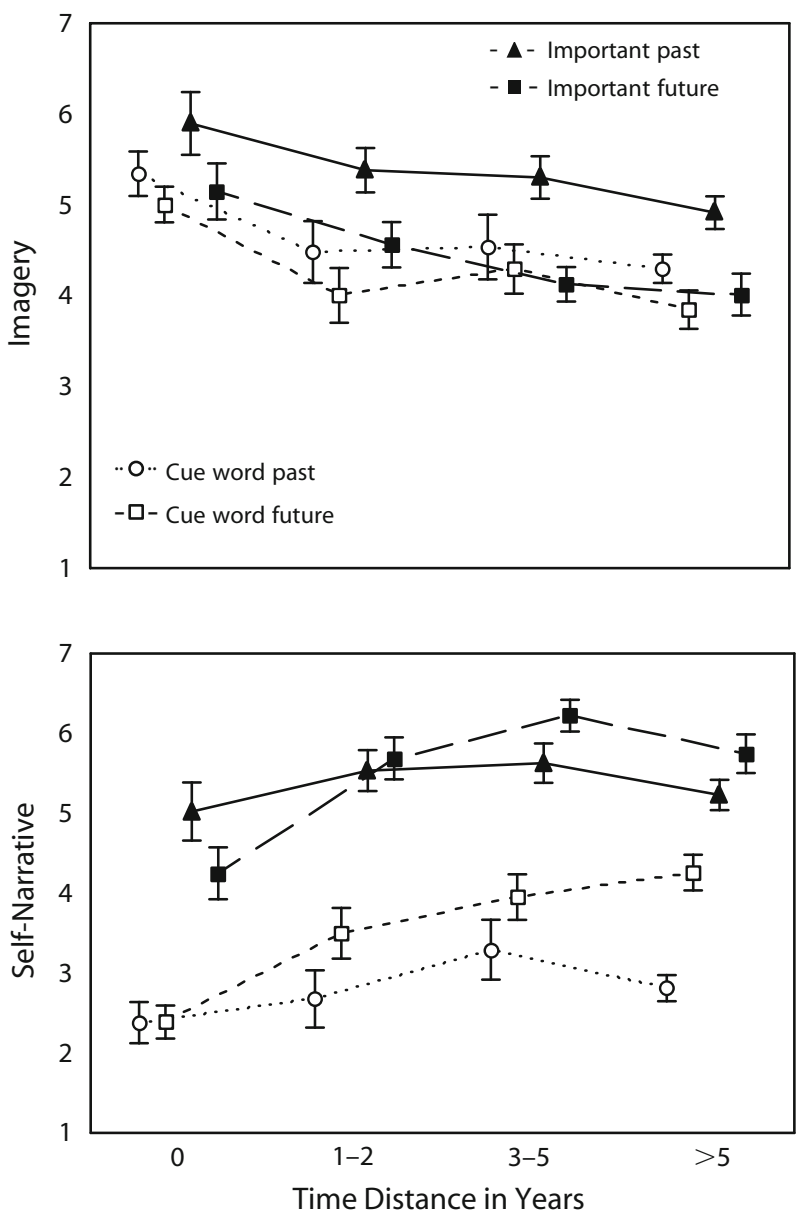

Figure 2. Top panel: Mean ratings of imagery for the four event categories as a function of temporal distance to the present measured in years. Bottom panel: Mean ratings of self-narrative for the four event categories as a function of temporal distance to the present measured in years. Vertical bars denote .95 confidence intervals.

ject variables included to control for subject variability) showed that temporal distance was a significant negative predictor for imagery $[t(2262)=-9.76, p<.0001, \beta=$ $-.19]$. As is illustrated by the top panel of Figure 2, the decrease ends after 1-2 years for the word-cued past and future events, whereas it continues beyond this point for the important future and past events. The top panel of Figure 2 also shows that the imagery scores for the important past events stay above the scores for the other three event categories at all temporal distances, which again underscores the special status of this event category. The bottom panel of Figure 2 illustrates that the scores for self-narrative tended to increase with increasing temporal distance and thus showed the pattern opposite to that for imagery. As was the case for the frequency of life script events (see Figure 1), this increase was reliable for events that were less than 5 years into the future or past, as evinced by a multiple regression analysis with self-narrative as the dependent variable and temporal distance in years as a predictor variable (together with 121 dummy-coded subject variables) and with events more than 5 years into the past/future filtered out $[t(1350)=16.46, p<.0001$, $\beta=.42]$.

We wanted to examine whether the relation between temporal distance and event characteristics, as illustrated in Figures 1 and 2, would be replicated for temporal distance measures in days for observations close in time. We therefore divided the 475 events that were less than 1 year away from the present into five time bins: $\leq 1$ day, $\geq 2$ and $\leq 7$ days, $\geq 8$ and $\leq 30$ days, $\geq 31$ and $\leq 90$ days, and $>90$ days (with a total of 108, 88, 108, 104, and 67 observations in each bin for all four event categories taken together). The distributions are shown in Figure 3. The top panel shows that even for events less than 1 year from the present, the proportion of life script events increases systematically with temporal distance as measured in days. A multiple regression analysis with life script reference as the dependent variable and temporal distance measured in days as a predictor variable (together with dummycoded subject variables to control for subject variability) showed a significant effect $[t(378)=4.57, p<.0001$, $\beta=.23]$. As is illustrated by the bottom panel of Figure 3, the same pattern is seen for self-narrative $[t(378)=7.04$, $p<.0001, \beta=.32]$. For imagery, on the other hand, a slight but significant inverse relation is present $[t(377)=$ $-2.40, p<.05, \beta=-.11$; see the bottom panel of Figure 3]. Thus, the relation between temporal distance and life script reference, self-narrative, and imagery, respectively, that we found for events more than a year into the past/future were replicated for events that were less than a year from the present.

\section{Relations Among Event Variables}

Having established that imagery and self-narrative consistently form two different dimensions that relate differently to temporal distance across all past and future events categories, we next ask how these sum scores are related to the other variables, including reference to the cultural life script. To address this question, we conducted a series of multiple regression analyses (with dummycoded subject variables to control for the fact that the 2,440 event cases were clustered around the 122 subjects). We conducted these analyses separately for each of the four event categories in order to see whether the same pattern would emerge across all four event categories. One series of analyses had imagery as the dependent variable and the remaining variables, including self-narrative, as predictors. ${ }^{2}$ The other series of analyses had self-narrative as the dependent variable and the remaining memory variables, including imagery, as predictors. The results are presented in Table 6. Both imagery and self-narrative were predicted by intensity and thought/talked. This pattern was consistent across the four event categories (see Table 4). In addition, reference to life script was a significant predictor for self-narrative consistently across the four event categories, whereas life script was unrelated to imagery. Belief was positively related to imagery, but not to self-narrative. Imagery and self-narrative did not predict one another for any of the four events (although inverse relations were seen for important future events), which underscores their role as two different dimensions in episodic remembering 

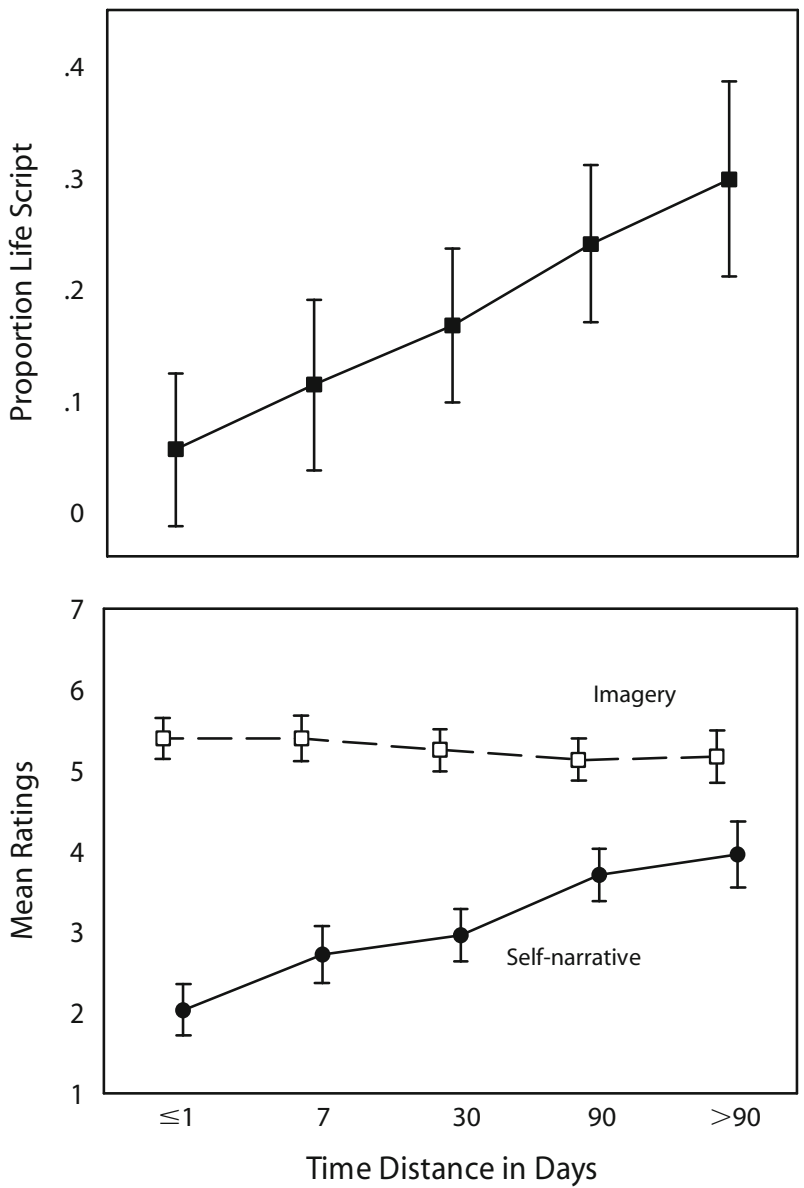

Figure 3. Top panel: Proportions of life script events as a function of temporal distance measured in days for events less than a year from the present. Bottom panel: Mean ratings of imagery and self-narrative as a function of temporal distance measured in days for events less than a year from the present. Vertical bars denote .95 confidence intervals.

and episodic future thinking. The fact that the regression analyses yielded highly similar results across the four event categories supports the view that the construction of these different types of autobiographical events draws upon similar cognitive processes (e.g., Schacter et al., 2007). At the same time, the statistical interactions and contentrelated differences that we showed in Tables 2-5 indicate that episodic remembering and future episodic thinking nonetheless relate differently to key components (or basic systems; Rubin, 2006) of such shared structures.

\section{DISCUSSION}

Previous work has demonstrated that episodic remembering and episodic future thinking are similarly affected by a variety of experimental manipulations. This has been taken as support for the idea that mental time travel in both temporal directions is governed by the same underlying neurocognitive system and that the most important role of episodic memory may be to facilitate episodic future thinking. Here, we used the standard cue word technique, as well as a request for important events, to elicit episodic remembering and episodic future thinking. We replicated and extended earlier findings by showing that imagined future events are less sensorially vivid and more personally significant than remembered past events. We also found that future events were markedly more emotionally positive and idyllic than past events. However, unlike previous work, these overall differences were qualified by a number of interactions. The interactions were mainly due to a larger effect of the important versus word-cued manipulation in the past, as compared with the future condition. Important past events were rated higher than any of the other three event categories on visual-auditory imagery, vividness, and p/reexperience and on whether the event was thought/talked about, and it was the only event category that had a U-shaped distribution of the emotion ratings, with more ratings at both extremes of the emotion scale than in the middle, showing the central role of both negative and positive emotional arousal for this category of events. An analysis of the content of the remembered and imagined events showed that important past events referred to emotionally upsetting experiences, such as accidents and other stressful episodes, much more frequently than did future events and also more frequently than did word-cued past events.

These findings support our claim that a request for important autobiographical events taps an encoding and maintenance effect that is present for episodic remembering but absent from (or considerably reduced for) episodic future thinking. Such effects are well described by autobiographical memory researchers in terms of memories of specific, emotional, and often unexpected events that hold an enduring influence on a person's thoughts, behavior, and sense of identity, such as turning points and anchoring events (Pillemer, 1998), self-defining memories (Singer \& Salovey, 1993), first experiences (Robinson, 1992), and vivid memories (Fitzgerald, 1988; Rubin \& Kozin, 1984). A similar effect is observed in posttraumatic stress disorder (PTSD), in which a highly negative event exerts a persistent influence on a person's well-being and ways of thinking about the self and the world (e.g., Berntsen \& Rubin, 2006, 2007; Ehlers \& Clark, 2000; Janoff-Bulman, 1989). Although such events do take place and generally are remembered very well, healthy people rarely imagine that they will occur in their future. For episodic future thinking, on the other hand, schematized regularities play a more central role than does correspondence with particular events simply because the events have not taken place and schema-based projections are left uncorrected.

This explanation is consistent with Addis, Pan, Vu, Laiser, and Schacter (2009), who proposed that future episodic thinking requires more constructive efforts than does episodic remembering because the future task requires event details to be extracted and recombined into novel events, whereas remembering involves recapitulation - that is, a process in which "the reactivation of sensory-perceptual and contextual details during retrieval recruits the neural regions which originally processed such information" (Addis et al., 2009, pp. 2236-2237). However, although this account may explain the increased sensory vividness 
Table 6

Multiple Regression Analyses Predicting Imagery and Self-Narrative for Word-Cued and Important Past and Future Events (Beta Weights)

\begin{tabular}{|c|c|c|c|c|c|c|c|c|}
\hline \multirow{3}{*}{$\begin{array}{l}\text { Independent } \\
\text { Variable }\end{array}$} & \multicolumn{4}{|c|}{ Imagery } & \multicolumn{4}{|c|}{ Self-Narrative } \\
\hline & \multicolumn{2}{|c|}{ Past Events } & \multicolumn{2}{|c|}{ Future Events } & \multicolumn{2}{|c|}{ Past Events } & \multicolumn{2}{|c|}{ Future Events } \\
\hline & Cue Word & Important & Cue Word & Important & Cue Word & Important & Cue Word & Important \\
\hline Intensity & $.446^{* * *}$ & $.354^{* * *}$ & $.376^{* * *}$ & $.429^{* * *}$ & $.326^{* * *}$ & $.196^{* * *}$ & $.297^{* * *}$ & $.329 * * *$ \\
\hline Thought/talked & $.159^{* *}$ & $.196^{* * *}$ & $.124^{* *}$ & $.235^{* * *}$ & $.348^{* * *}$ & $.277^{* * *}$ & $.309^{* * *}$ & $.221^{* * *}$ \\
\hline Valence & -.040 & -.010 & $.135^{* *}$ & $.154^{* * *}$ & $.130^{* *}$ & .024 & $.154^{* * *}$ & $.235^{* * *}$ \\
\hline Belief & $.283^{* * *}$ & $.297^{* * *}$ & $.223^{* * *}$ & $.064^{*}$ & -.030 & .098 & .030 & .018 \\
\hline Life script & -.012 & $-.089^{* *}$ & -.054 & -.045 & $.174^{* * *}$ & $.158^{* * *}$ & $.293^{* * *}$ & $.375^{* * *}$ \\
\hline Perspective & $-.126^{* *}$ & $-.125^{* *}$ & -.061 & -.054 & .062 & .054 & $.080^{*}$ & .035 \\
\hline Distance, years & $-.184^{* * *}$ & $-.073^{*}$ & $-.091^{*}$ & -.001 & -.053 & $-.132^{* *}$ & $.232^{* * *}$ & $.102^{* *}$ \\
\hline \multicolumn{9}{|l|}{ Composite scores } \\
\hline Imagery & - & - & - & - & -.030 & -.002 & -.090 & $-.208^{* * *}$ \\
\hline Self-narrative & -.031 & -.002 & -.082 & $-.152^{* * *}$ & - & - & - & - \\
\hline
\end{tabular}

of episodic remembering, as compared with episodic future thinking, it does not explain why representations of the future are more positively biased than representations of the past. We propose that episodic future thinking involves more positive emotion than does episodic remembering, because of more uncorrected positive illusions for the future than for the past. This explanation draws upon multiple sources of evidence that ordinary human thought is characterized by positive illusions - among other things, in terms of unrealistically positive self-evaluations, an exaggerated feeling of control, and an unrealistic optimism about the future (e.g., Markus \& Nurius, 1986; Taylor \& Brown, 1988). As was argued by Taylor and Brown, positive distortions of reality may be adaptive by motivating individuals to engage in social relationships, as well as in creative and productive work. Consistent with this idea, Cacioppo and colleagues introduced the notion of a positivity offset, formulated as "a tendency for a weak positive (approach) output at a zero input" (see Cacioppo \& Gardner, 1999, p. 205), which means that the tendency to approach a neutral stimulus is stronger than the tendency to avoid it. The positivity offset motivates organisms in a neutral environment to approach novel objects and stimuli and to expect positive outcomes of unknown future events. Episodic remembering also shows positive distortionsfor example, in terms of a tendency to misrepresent past reality in ways that boost the accomplishments and abilities of the current self (Wilson \& Ross, 2003). However, at the same time, memories of highly negative events are very well remembered (see, e.g., McGaugh, 2003, 2004, for reviews), which makes sense, among other things, because such events form important corrections to positive illusions (Janoff-Bulman, 1989) and thus constitute important learning episodes that increase the chances of survival (Baumeister, Bratslavsky, Finkenauer, \& Vohs, 2001).

The present study also documented a central role for cultural life scripts for both episodic remembering and episodic future thinking. The large majority of the important past and future events referred to events that are part of the cultural life script - such as beginning school, falling in love, getting married, having children. The frequency of cultural life script events was much lower for the word- cued future and past events, providing evidence that the role of cultural life scripts varies systematically with how autobiographical events are sampled (Berntsen \& Rubin, 2004). We found that the frequency of cultural life script events increased systematically with increasing temporal distance to the present for all four event categories. This suggests that cultural life scripts may be especially important for guiding mental time travel across longer temporal distances. Cultural life scripts - as well as other forms of culturally transmitted temporal structures (e.g., Friedman, 1992) - are likely to significantly enlarge the subjective time horizon of adult humans, relative to the one of children and nonhuman species (Berntsen \& Jacobsen, 2008; Roberts, 2002).

We identified two different dimensions in episodic remembering and episodic future thinking that showed a similar pattern across all four past and future event categories. One was imagery, referring to sensory imagery and a subjective feeling of reliving (or preliving) the event. The other was self-narrative, referring to how personally important and central to the life story and identity the remembered or imagined event was considered to be. Consistently across all four event categories, imagery dropped with increasing distance to the present, whereas self-narrative increased with increasing temporal distance to the present. Multiple regression analyses showed that both of the two dimensions were predicted by emotional intensity and how much the events had been thought and talked about, whereas self-narrative, but not imagery, was also predicted by reference to the cultural life script. This suggests that life scripts play an important role for providing structure and meaning to the narrative understanding of our personal past, as well as our personal future.

The present distinction between imagery and selfnarrative agrees with work conducted on autobiographical memory for past events. In a number of studies, Rubin and colleagues have demonstrated an intimate relationship between visual imagery and the subjective feeling of reliving the past event (for reviews, see, e.g., Rubin, 2006; Rubin et al., 2003). Narrative reasoning about the event, on the other hand, is shown to be a different component of autobiographical remembering governed by different 
rules and schemata (Rubin, 2006). We have provided evidence here that the relevance of this conceptual separation is not limited to autobiographical memory for past events but is equally relevant for episodic future thinking and that these two dimensions are dissimilarly related to temporal distance for both future and past events. The present distinction between self-narrative and imagery can also be seen as mapping on to Conway's (2005) distinction between life story structures and event-specific details, respectively.

Our finding that imagery dropped with increasing temporal distance, whereas self-narrative increased, agrees with temporal construal theory (Trope \& Liberman, 2003), according to which people form more abstract representations (high-level construals) of temporally distant events and more concrete representations (low-level construals) of temporally close events. According to Trope and Liberman, high-level construals consist of general, decontextualized features conveying the essential information about an event (e.g., having a child), whereas lowlevel construals include concrete, contextual, and accidental details (e.g., changing diapers). Our finding that imagery and self-narrative showed the same differential pattern across all four event categories supports the idea that episodic remembering and future episodic thinking are served by the same underlying structures. At the same time, the fact that imagery was higher for episodic remembering and self-narrative was higher for future episodic thinking, as well as the interactions caused by the cuing manipulation, supports our claim that the two processes nonetheless interact differently with key components of such shared structures.

Maybe the most intriguing question concerning the relation between episodic remembering and episodic future thinking is how we avoid mixing them up in daily life (Johnson \& Raye, 1981). Although we often misremember details and may falsely adopt entire fictive events to be part of our personal past (see Lindsay, 2008, for a review), in most cases we are capable of distinguishing facts from fiction. Since Aristotle, philosophers have tried to explain this enigma. Some have argued that images of memory have different characteristics than do images of imagined events (see Brewer, 1996, for a review). Others have proposed that imagining and remembering are characterized by fundamentally different functionalities (Ricœur, 2004). Consistent with both views, we have argued that differences between episodic remembering and future thinking may be conceptualized in terms of an encoding and maintenance effect that is inherent to the former but absent from (or considerably reduced for) the latter. This implies perceptually richer and less idyllic representations of past than of future events, consistent with our findings.

In an applied perspective, studies of populations with psychological disorders suggest that the relation between episodic remembering and future episodic thinking is intricate and may break down in response to highly stressful experiences. In emotional disorders, such as PTSD, complicated grief, and/or depression, highly stressful experiences may come to serve as reference points for future expectations and lead to a sense of a foreshortened future, hopelessness, and/or suicidal behavior (e.g., Berntsen \& Rubin, 2006, 2007; Boelen, 2009; Conaghan \& Davidson, 2002; Ehlers \& Clark, 2000; Kuyken \& Brewin, 1994; Williams et al., 1996). Examining the relation between episodic remembering and episodic future thinking along the lines that we have delineated here is likely to deepen our understanding of such disorders.

\section{AUTHOR NOTE}

This work was supported by the Danish National Research Foundation, as well as a collective research project grant from the Danish Research Council for the Humanities to the first author and by a postdoctoral stipend from the Danish Research Council for the Humanities to the second author. We thank David C. Rubin and two anonymous reviewers for comments and Anne Scharling Rasmussen, Morten Bech Sørensen, and Tua Preuss for their help. Correspondence concerning this article should be addressed to D. Berntsen, Department of Psychology, Center on Autobiographical Memory Research, Aarhus University, Nobelparken, Jens Chr. Skousvej 4, 8000 Aarhus C., Denmark (e-mail: dorthe@psy.au.dk).

\section{REFERENCES}

Addis, D. R., Pan, L., Vu, M.-A., Laiser, N., \& Schacter, D. L. (2009). Constructive episodic simulation of the future and the past: Distinct subsystems of a core brain network mediate imagining and remembering. Neuropsychologia, 47, 2222-2238.

Addis, D. R., Wong, A. T., \& Schacter, D. L. (2007). Remembering the past and imagining the future: Common and distinct neural substrates during event construction and elaboration. Neuropsychologia, 45, 1363-1377. doi:10.1016/j.neuropsychologia.2006.10.016

AdDis, D. R., Wong, A. T., \& Schacter, D. L. (2008). Age-related changes in the episodic simulation of future events. Psychological Science, 19, 33-41. doi:10.1111/j.1467-9280.2008.02043.x

Atance, C. M. (2008). Future thinking in young children. Current Directions in Psychological Science, 17, 295-298. doi:10.1111/j.1467 $-8721.2008 .00593 . \mathrm{x}$

Atance, C. M., \& O’Neill, D. K. (2001). Episodic future thinking. Trends in Cognitive Sciences, 5, 533-539. doi:10.1016/S1364 $-6613(00) 01804-0$

Baumeister, R. F., Bratslavsky, E., Finkenauer, C., \& Vohs, K. D. (2001). Bad is stronger than good. Review of General Psychology, 5, 323-370. doi:10.1037/1089-2680.5.4.323

Bergenholtz, H. (1992). Dansk Frekvensordbog [Danish dictionary of word frequencies]. Copenhagen: Gads Forlag.

Berntsen, D. (2009). Involuntary autobiographical memories. An introduction to the unbidden past. Cambridge: Cambridge University Press.

Berntsen, D., \& JACOBSEN, A. S. (2008). Involuntary (spontaneous) mental time travel into the past and future. Consciousness \& Cognition, 17, 1093-1104. doi:10.1016/j.concog.2008.03.001

Berntsen, D., \& Rubin, D. C. (2004). Cultural life scripts structure recall from autobiographical memory. Memory \& Cognition, 32, 427-442.

Berntsen, D., \& Rubin, D. C. (2006). Centrality of event scale. A measure of integrating a trauma into one's identity and its relation to posttraumatic stress disorder symptoms. Behaviour Research \& Therapy, 44, 219-231.

Berntsen, D., \& Rubin, D. C. (2007). When a trauma becomes a key to identity: Enhanced integration of trauma memories predicts posttraumatic stress disorder symptoms. Applied Cognitive Psychology, 21, 417-431. doi:10.1002/acp. 1290

Boelen, P. A. (2009). The centrality of a loss and its role in emotional problems among bereaved people. Behaviour Research \& Therapy, 47, 616-622. doi:10.1016/j.brat.2009.03.009

BoHN, A. (in press). Generational differences in cultural life scripts and life story memories of younger and older adults. Applied Cognitive Psychology.

BoHn, A., \& BERnTSEn, D. (2008). Life story development in childhood: The development of life story abilities and the acquisition of cultural life scripts from late middle childhood to adolescence. Developmental Psychology, 44, 1135-1147. doi:10.1037/0012-1649.44.4.1135 
Botzung, A., Denkova, E., \& Manning, L. (2008). Experiencing past and future personal events: Functional neuroimaging evidence on the neural bases of mental time travel. Brain \& Cognition, 66, 202-212. doi:10.1016/j.bandc.2007.07.011

BREWER, W. F. (1996). What is recollective memory? In D. C. Rubin (Ed.), Remembering our past: Studies in autobiographical memory (pp. 19-66). Cambridge: Cambridge University Press.

Brown, W. P., \& URE, D. M. (1969). Five rated characteristics of 650 word association stimuli. British Journal of Psychology, 60, 233-249.

CACIOPPO, J. T., \& GARDNER, W. L. (1999). Emotion. Annual Review of Psychology, 50, 191-214. doi:10.1146/annurev.psych.50.1.191

COHEN, J., \& CoHEN, P. (1983). Applied multiple regression/correlation analysis for the behavioral sciences (2nd ed.). Hillsdale, NJ: Erlbaum.

Conaghan, S., \& Davidson, K. M. (2002). Hopelessness and the anticipation of positive and negative future experiences in older parasuicidal adults. British Journal of Clinical Psychology, 41, 233-242. doi:10.1348/014466502760379208

Conway, M. A. (2005). Memory and the self. Journal of Memory \& Language, 53, 594-628. doi:10.1016/j.jml.2005.08.005

Crovitz, H. F., \& Schiffman, H. (1974). Frequency of episodic memories as a function of their age. Bulletin of the Psychonomic Society, 4, $517-518$

D'Argembeau, A., Raffard, S., \& Van der Linden, M. (2008). Remembering the past and imagining the future in schizophrenia. Journal of Abnormal Psychology, 117, 247-251. doi:10.1037/0021 -843X.117.1.247

D'Argembeau, A., \& Van der Linden, M. (2004). Phenomenal characteristics associated with projecting oneself back into the past and forward into the future: Influence of valence and temporal distance. Consciousness \& Cognition, 13, 844-858. doi:10.1016/j .concog.2004.07.007

Ehlers, A., \& Clark, D. M. (2000). A cognitive model of posttraumatic stress disorder. Behaviour Research \& Therapy, 38, 319-345. doi:10.1016/S0005-7967(99)00123-0

FitZGERALD, J. M. (1988). Vivid memories and the reminiscence phenomenon: The role of a self narrative. Human Development, 31, 261-273.

Friedman, W. J. (1992). Children's time memory: The development of a differentiated past. Cognitive Development, 7, 171-187. doi:10.1016/0885-2014(92)90010-O

Galton, F. (1907). Inquiries into human faculty and its development. London: Dent.

Hassabis, D., Kumaran, D., Vann, S. D., \& Maguire, E. A. (2007). Patients with hippocampal amnesia cannot imagine new experiences. Proceedings of the National Academy of Sciences, 104, 1726-1731. doi:10.1073/pnas.0610561104

JANOFF-Bulman, R. (1989). Assumptive worlds and the stress of traumatic events: Applications of the schema construct. Social Cognition, 7, 113-136.

Johnson, M. K., \& RaYe, C. L. (1981). Reality monitoring. Psychological Review, 88, 67-85. doi:10.1037/0033-295X.88.1.67

Klein, S. B., Loftus, J., \& Kinlstrom, J. F. (2002). Memory and temporal experience: The effects of episodic memory loss on an amnesic patient's ability to remember the past and imagine the future. Social Cognition, 20, 353-379. doi:10.1521/soco.20.5.353.21125

KUYKEN, W., \& BREWIN, C. R. (1994). Intrusive memories of childhood abuse during depressive episodes. Behaviour Research \& Therapy, 32, 525-528. doi:10.1016/0005-7967(94)90140-6

Lachman, M. E., Röcke, C., Rosnick, C., \& RyfF, C. D. (2008). Realism and illusion in Americans' temporal views of their life satisfaction: Age differences in reconstructing the past and anticipating the future. Psychological Science, 19, 889-897. doi:10.1111/j.1467 $-9280.2008 .02173 . \mathrm{x}$

LARSEN, S. F. (1998). What is it like to remember? On the phenomenal qualities of memory. In C. P. Thompson, D. J. Herrmann, D. Bruce, J. D. Read, D. G. Payne, \& M. P. Toglia (Eds.), Autobiographical memory: Theoretical and applied perspectives (pp. 163-190). Mahwah, NJ: Erlbaum.

LiNDSAY, D. S. (2008). Source monitoring. In J. Byrne (Series Ed.) \& H. L. Roediger III (Vol. Ed.), Learning and memory: A comprehensive reference. Vol. 2: Cognitive psychology of memory (pp. 325-348). Amsterdam: Elsevier.

Lishman, W. A. (1974). The speed of recall of pleasant and unpleasant experiences. Psychological Medicine, 4, 212-218.
Markus, H., \& Nurius, P. (1986). Possible selves. American Psychologist, 41, 954-969. doi:10.1037/0003-066X.41.9.954

McGaugh, J. L. (2003). Memory and emotion: The making of lasting memories. New York: Columbia University Press.

McGaugh, J. L. (2004). The amygdala modulates the consolidation of memories of emotionally arousing experiences. Annual Review of Neuroscience, 27, 1-28. doi:10.1146/annurev.neuro.27.070203.144157

Neugarten, B. L., Moore, J. W., \& Lowe, J. C. (1965). Age norms, age constraints, and adult socialization. American Journal of Sociology, 70, 710-717.

Newby-Clark, I. R., \& Ross, M. (2003). Conceiving the past and future. Personality \& Social Psychology Bulletin, 29, 807-818. doi:10.1177/0146167203029007001

Okuda, J., Fuji, T., Ohtake, H., Tsukiura, T., Tanji, K., Suzuki, K., ET AL. (2003). Thinking of the future and past: The roles of the frontal pole and the medial temporal lobes. NeuroImage, 19, 1369-1380. doi:10.1016/S1053-8119(03)00179-4

Pillemer, D. B. (1998). Momentous events, vivid memories. Cambridge, MA: Harvard University Press.

Pillemer, D. B. (2003). Directive functions of autobiographical memory: The guiding power of the specific episode. Memory, 11, 193-202. doi:10.1080/741938208

Ricceur, P. (2004). Memory, history, forgetting (K. Blamey \& D. Pellauer, Trans.). Chicago: University of Chicago Press.

Roberts, W. A. (2002). Are animals stuck in time? Psychological Bulletin, 128, 473-489. doi:10.1037/0033-2909.128.3.473

Robinson, J. A. (1992). First experiences: Contexts and functions in personal histories. In M. A. Conway, D. C. Rubin, H. Spinnler, \& W. Wagenaar (Eds.), Theoretical perspectives on autobiographical memory (pp. 223-239). Utrecht: Kluwer.

Rubin, D. C. (2006). The basic-systems model of episodic memory. Perspectives on Psychological Science, 1, 277-311.

Rubin, D. C., Berntsen, D., \& Hutson, M. (2009). The normative and the personal life: Individual differences in life scripts and life story events among USA and Danish undergraduates. Memory, 17, 54-68. doi:10.1080/09658210802541442

Rubin, D. C., \& KozIn, M. (1984). Vivid memories. Cognition, 16, 8195. doi:10.1016/0010-0277(84)90037-4

Rubin, D. C., Schrauf, R. W., \& Greenberg, D. L. (2003). Belief and recollection of autobiographical memories. Memory \& Cognition, 31, 887-901.

Rubin, D. C., \& Schulkind, M. D. (1997a). Distribution of important and word-cued autobiographical memories in 20-, 35-, and 70-yearold adults. Psychology \& Aging, 12, 524-535. doi:10.1037/0882 $-7974.12 .3 .524$

Rubin, D. C., \& Schulkind, M. D. (1997b). Properties of word cues for autobiographical memory. Psychological Reports, 81, 47-50.

SCHACTER, D. L., \& ADDIS, D. R. (2007). The cognitive neuroscience of constructive memory: Remembering the past and imagining the future. Philosophical Transactions of the Royal Society B, 362, 773-786.

Schacter, D. L., Addis, D. R., \& Buckner, R. L. (2007). Remembering the past to imagine the future: The prospective brain. Nature Reviews Neuroscience, 8, 657-661.

Schank, R. C., \& Abelson, R. P. (1977). Scripts, plans, and knowledge. In P. N. Johnson-Laird \& P. C. Wason (Eds.), Thinking: Readings in cognitive science (pp. 421-435). Cambridge: Cambridge University Press.

Schlagman, S., Schulz, J., \& Kvavilashvili, L. (2006). A content analysis of involuntary autobiographical memories: Examining the positivity effect in old age. Memory, 14, 161-175. doi:10 $.1080 / 09658210544000024$

Singer, J. A., \& SAlovey, P. (1993). The remembered self: Emotion and memory in personality. New York: Free Press.

Spreng, R. N., \& Levine, B. (2006). The temporal distribution of past and future autobiographical events across the lifespan. Memory \& Cognition, 34, 1644-1651.

Suddendorf, T., \& Corballis, M. C. (2007). The evolution of foresight: What is mental time travel and is it unique to humans? Behavioral \& Brain Sciences, 30, 299-313.

SzPUNAR, K. K. (in press). Episodic future thought: An emerging concept. Perspectives on Psychological Science.

SzPunar, K. K., \& McDermott, K. B. (2008). Episodic future thought and its relation to remembering: Evidence from ratings of subjective 
experience. Consciousness \& Cognition, 17, 330-334. doi:10.1016/ j.concog.2007.04.006

Szpunar, K. K., Watson, J. M., \& McDermott, K. B. (2007). Neural substrates of envisioning the future. Proceedings of the National Academy of Sciences, 104, 642-647. doi:10.1073/pnas.0610082104

TAYLOR, S. E., \& BROWN, J. D. (1988). Illusion and well-being: A social psychological perspective on mental health. Psychological Bulletin, 103, 193-210. doi:10.1037/0033-2909.103.2.193

Thompson, C. P., Skowronski, J. S., Larsen, S. F., \& Betz, A. L. (1996). Autobiographical memory: Remembering what and remembering when. Mahwah, NJ: Erlbaum.

Trope, Y., \& Liberman, N. (2003). Temporal construal. Psychological Review, 110, 403-421. doi:10.1037/0033-295X.110.3.403

Tulving, E. (1985). Memory and consciousness. Canadian Psychology, 26, 1-26.

Walker, W. R., Skowronski, J. J., \& Thompson, C. P. (2003). Life is pleasant-and memory helps to keep it that way! Review of General Psychology, 7, 203-210. doi:10.1037/1089-2680.7.2.203
Williams, J. M. G., Ellis, N. C., Tyers, C., Healy, H., Rose, G., \& MacLeod, A. K. (1996). The specificity of autobiographical memory and imageability of the future. Memory \& Cognition, 24, 116-125.

Wilson, A. E., \& Ross, M. (2003). The identity function of autobiographical memory: Time is on our side. Memory, 11, 137-149. doi:10.1080/741938210

\section{NOTES}

1. To do this calculation, the original 5-point scales for identity and life story were accommodated to form 7-point scales.

2. Reaction was not included as a predictor variable, because of its strong relation to the predictor variable emotional intensity.

(Manuscript received June 9, 2009; revision accepted for publication September 28, 2009.) 